\title{
Globalization and Resistance
}

The Tibetan Case

\author{
Molly Chatalic
}

Introduction

When discussing the question of globalization and its effect on minority populations, as well as the effect in turn of minorities on the future of the world, the Tibetan case presents multiple facets and raises numerous questions related to this issue. The Tibetan minority finds itself having to negotiate between an imposed globalization and one which is voluntarily embraced. Indeed Tibetans are caught between two aspects of this phenomenon: on the one hand, they are coping with and resisting Chinese occupation and colonialism which is itself reinforced by certain effects of globalization (i.e. the need to secure strategic positions and especially resources; the constraints linked to entering the stage of international powers, the adoption of consumerism and materialism) and on the other hand, they are learning to skilfully employ features of globalization as tools and strategies of resistance (in terms of communication, economic mobility, financial and legal assistance, education, etc.). As we shall see, they are becoming citizens of the world while upholding their primary identity as Tibetans.

\section{The Tibetans: A Global Minority Community?}

Tibetans are a minority in China, in what they consider as Tibet in China, and in exile, but not yet within the Tibet Autonomous Region (TAR). ${ }^{1}$ As an ethnic minority group, Tibetans come 9 th in terms of numbers ( 5.8 million) in the list of 56 national minorities (shaoshu minzu) recognized in China. As opposed to the Tibet Autonomous Region defined by China, the territory they themselves consider as historically representing an independent Tibet covers about 1/4th of China. ${ }^{2}$ Tibetans have been escaping their country over the past six decades,

$1<$ www.tibet.org/Activism/Rights/poptransfer.html>, visited on 31 July 2013.

2 The Tibet Autonomous Region covers 1.2 million square kilometers. The surface of the area considered as Tibet by Tibetans covers 3.8 million square kilometers (approximately the equivalent of Western Europe) and includes TAR, Qinghai, parts of Gansu, Sichuan and Yunnan.

(C) MOLly CHATAlic, 2015 | DOI 10.1163/9789004282087_007

This is an open access chapter distributed under the terms of the prevailing CC-BY-NC License at the time of publication. 
ever since the "peaceful liberation" of the country by the Chinese Communists. In exile and in the West, to describe the experience of Tibetans within China and the fact that many of them live in exile now, terms previously used in the case of Jewish populations such as genocide and diaspora are now also commonly applied in the case of Tibetans as in that of other minorities, although the first term is usually qualified and used in the expression "cultural genocide." Within the current international context of a rapidly changing world, the Tibetan case could perhaps serve as a paradigm for other repressed or exiled minorities due to certain specificities of their particular group: the choice of non-violence, their adaptation in exile while retaining a very strong sense of primary identity, and their dream of independence or of returning to their homeland one day, and this after sixty years of what they consider as a state of occupation of their country. This paper will deal with both the Tibetans still living within Chinese-occupied Tibet and those living in exile, with the view that they constitute a whole as a global minority community and that their sense of belonging to one people transcends national boundaries imposed by colonialism and exile.

Indeed, colonialism does not only pertain to European history: there have been numerous examples of colonialism as well in countries of the Middle East and Asia (such as in Japan, China, former Siam, India, etc.). Chinese colonization (as seen from the Tibetan viewpoint) since the 1950s has had a major impact on Tibetan society and has led to the emergence of a Tibetan diaspora in several phases, starting with the flight of 80,000 Tibetans into exile in India in 1959 (in fact many wealthier families had already established themselves there in the preceding decade, foreseeing the difficulties to come). Of course, Tibet had already been coveted in the past by the Chinese, British and Russians, but the Liberation Army's offensive at the end of the 1950s ended in a decisive take-over and in the permanent flight into exile of the Dalai Lama who represents a focal point for the identity make-up of the majority of Tibetans. ${ }^{3}$

Until 2008, between 2,000 and 3,000 Tibetans had continued to escape over the border into Nepal and India every year (usually after a two or three-week trek over the mountains). This escape is motivated by unbearable living conditions experienced inside Tibet by Tibetans due to economic, cultural, religious, and educational discrimination, to constant surveillance and police control,

3 The Dalai Lama is usually qualified as being the "sun" for Tibetans, his counterpart or the "moon" being another religious leader, the Panchen Lama. These qualifications illustrate the Tibetan propensity to use natural symbols in their depiction of daily reality and also point to the vital and life-sustaining role these two figureheads play in the identity make-up of the Tibetan community. 
and to lack of freedom of speech and opinion. Some Tibetans also simply wish to meet the Dalai Lama once in their life before undertaking the risky journey back. With the change of government in $\mathrm{Nepal}^{4}$ and the enforcement of border controls by the Chinese, the number of refugees has decreased sharply. ${ }^{5}$ No passports have been issued to Tibetans so far in 2013 by Chinese authorities in Tibet, meaning that no legal means of leaving Tibet are available. The diaspora (established mainly in India, Western Europe and North America) represents around 150,000 people, and its members continue to be mobile, moving from one country to another following family or clan links, job opportunities and settlement programs. ${ }^{6}$ The mobility which characterizes this minority in exile seems to stem from and to illustrate the lack of long-term commitment of most of its members to remaining in the different countries where they have settled out of necessity. The dream of going back to Tibet one day, even if one may doubt that this will ever be possible, is still very present for many and in the meanwhile, the world outside of Tibet, especially India, Nepal, Western Europe, Taïwan, Japan and Australia, constitutes a place of passage and mobility in a secure and relatively free environment.

As in the case of other minorities, the Tibetans exist in part as a diaspora, but a tightly linked one. There is nevertheless a certain cultural and educational schism between Tibetans born in Tibet and those born in the diaspora, especially for the second and third generations which have been more prone to acculturation. This breach is also due mainly to the variation in exposure to globalization and to the differences in educational opportunities within and outside of Tibet which are available to Tibetans. Nevertheless, the high degree of networking, of solidarity with newcomers and of family and clan bonds

4 Nepal was an absolute monarchy up until 1990, when it became a parliamentary monarchy. The massacre of the Royal family by the Crown Prince led to King Gayendra taking power, dissolving the Parliament and imposing martial law, in part to counter a Maoist insurgency which had been ongoing since 1996. A national uprising in 2006 finally saw the Parliament reinstated in its powers and Nepal became a federal Republic in May 2008, when the monarchy was abolished.

5 The Nangpa-la Pass incident in September 2006 during which a party of Tibetans fleeing Tibet were shot at from behind by Chinese soldiers (one nun was killed) in full view of a group of Western mountaineers made international headlines and is an illustration of the dangers that Tibetans face in attempting to cross the borders into neighboring countries. $<$ www.dailymail.co.uk/home/moslive/article-1285035/A-murder-shadow-Everest -Why-innocent-Tibetan-nun-gunned-Chinese-soldiers-Himalayas.html>, visited on 31 July 2013. See also <www.nytimes.com/2013/04/14/world/asia/china-makes-inroads-in-nepal-stemming -tibetan-presence.html?pagewanted=1\&_r=1\&ref=global-home $>$, visited on 1 August 2013.

6 For example, the Tibetan United States Resettlement Project in 1992 allowed for the establishment of one thousand Tibetans in the United States. 
allow for mobility of individuals among the different diasporic communities established in various countries. This resilience of community, whether inside Tibet or in exile, is mirrored in the resilience of the Tibetan spirit, in the importance they grant to their fundamental ethnic identity which may find its source in a sense of responsibility to the world. Although they do not consider themselves as a "chosen people" (as they are not people of the Book, but "insiders," which is the Tibetan word for Buddhists), they do have a sense of their specificity or role on the global level. The small number of their community and the desire to maintain their ethnic identity may explain the tendency among Tibetans so far to raise parentless Tibetan children within the Tibetan community instead of having them adopted outside the community, and to marry among themselves, two communitarian trends which are not always easy to follow in the context of globalization but which characterize many minority communities concerned with their long-term survival.

The majority of Tibetans living inside Tibet (i.e. the "Tibet Autonomous Region," Qinghai and parts of the different provinces of Gansu, Sichuan and Yunnan) express a feeling of being more and more marginalized on all levels by the dominant $\mathrm{Han}^{7}$ society and live in what one French journalist (Cyril Payen) recently qualified as an Orwellian situation, as prisoners in their own country, which is being turned into a fake-Tibetan Disneyland for Chinese tourists, in contrast to the mythical Shangri-la like image it has long possessed in the world's imagination. This Disneyfication is apparent in the control, ${ }^{8}$ reconstruction and rehabilitation of temples for tourists, in the existence of official dance troups and groups, in the promotion of Tibet as an exotic destination within reach. But as in other Disneylands or theme parks, which are geared at offering immediate pleasure in a safe environment, the outer shell is empty of authenticity and the actors must play fake roles to satisfy the public. Although the Chinese tourists probably do not realize it, the Tibetan population is under very close watch. The surveillance cameras in Lhasa have now been supplemented by a 'grid system' which closely monitors all the inhabitants and happenings neighbourhood by neighbourhood, block by block, and building by building, thus reinforcing the "Big Brother" simile. ${ }^{9}$ The architecture

7 The Han population constitutes the main ethnic group in China today and represents about $93 \%$ of the Chinese population. It is distinct from other groups such as the Manchus, the Mongols, the Huis, the Tibetans and other minority ethnic groups.

8 The Drepung Monastery near Lhasa charges tourists for entrance, photos and filming. Monks receive the fees and this income is controlled by policemen. Only a small percentage is returned to the monastery:<www.rts.ch/video/emissions/mise-au-point/5326823-le-tibet -made-in-china.html $>$, visited on 29 October 2013.

9 "Security in Tibet: Grid locked," in The Economist (22 June 2013), 53-54. 
of the capital itself, Lhasa, has become mostly Chinese. Plans for a new shopping mall right next to the Potala are underway and the foundations being laid in the middle of the old streets of Lhassa forbode the worst for the old traditional houses lining these streets. The destruction of the older neighbourhoods and houses is justified by China in that modernism always destroys old traditions to make things better. The historiographical debate about which civilization, that of China or that of Tibet, is older and greater as well as what political ties existed between them is an ongoing one today among Chinese, Tibetan and Western scholars.

\section{Adapting to a Global World, Adopting New Tools}

Whether they are "insiders" or exiles, whether they live alone or in a community, Tibetans have adapted to this forced modernization due to the dual effects of colonization and globalization and are learning to use all the modern tools of communication to create a worldwide network, a global Tibetan community. In Tibet proper, the use of iPhones and applications such as WeChat allow for rapid communication and the sharing of photos and information with Tibetans outside of Tibet. However, WeChat is feared to be monitored and used by the Chinese government to track dissident activity. A similar application, Yakchat, "developed by Iron Rabbits, a virtual and anonymous hacker collective that develops a number of open source apps and supports Tibetan activism," uses servers located outside of China but is not yet easy to access in China and is so far used mainly by Tibetans in exile. ${ }^{10}$ The broadcasts of Voice of America and Radio Free Asia are accessed with satellite dishes which recently underwent an eradication campaign in Tibet. More and more websites and blogs in Tibetan are appearing on the Internet, and Wikipedia rates its Tibetan-language version as 139th in terms of its number of articles (a little over six thousand articles in Tibetan, with almost a thousand active users). ${ }^{11}$ Apple computers and iPhones are favored by Tibetans within and outside of China because they incorporate Tibetan fonts in their list of standard languages for direct screen use. Of course, there is great censorship in China, and currently, Tibetans found to harbour pictures of the Dalai Lama, of the Tibetan flag or of self-immolators on their mobile phones are arrested

\footnotetext{
$10<$ www.theguardian.com/world/2012/dec/07/wechat-chinese-social-media-app $>$ and $<$ techpresident.com/news/wegov/24198/yakchat-countering-wechat-'curse'-tibet\# .Ufazks8uQE4.twitter $>$, visited on 3 August 2013.

$11<$ meta.wikimedia.org/wiki/List_of_Wikipedias>, visited on 12 June 2013.
} 
and imprisoned, as are those Tibetans who transmit photos and information to people outside of China. Beatings and torture are regular parts of the arrest and imprisonment procedures. Nonetheless, Tibetans continue to communicate with each other across the borders, whether for private purposes (family, business) or to publicize what is happening in Tibet. Thus global means of communication contribute to Tibetan activism and resistance inside and outside of Tibet.

Tibetans' resistance to being assimilated by Chinese society or to being acculturated in exile while adapting to globalization is currently being expressed through an outburst of literary and artistic creation. In literature, the use of implicit language (through metaphors and traditional images) prevails within Tibet (although some knowingly risk almost immediate arrest, torture and imprisonment by being explicit in their writing or declarations). Recently arrested writers in Tibet include Gangkye Dupakyab, Samdup, Yudrang and Drensal, who had allegedly established a group called "Marchung Ngogol Tsokpa," which translates roughly as "Red Movement," or the writer called Tsultrim Gyaltsen. A poet, Lobsang Namgyal, was also arrested in 2013 for his book of poems expressing Tibetan identity. Tibetans writing in exile and in English include such writers as Jamyang Norbu, Buchung Sonam, Tsering Wangmo Dhompa and Tenzin Tsundue. All of these writers refer to Tibetan identity in their works which stand as a testimony of what Tibetans experience and feel inside and outside of Tibet. Their impact is limited to the international audience interested in the Tibetan issue. In general, autobiographies are the most successful in reaching this international readership. However, with the use of the Internet, more and more non-Tibetans with an interest in literature are gaining access to blogs and sites in English about Tibetan writers and poets as well.

Songs are also a favored medium of expression for Tibetans and Youtube is replete with traditional and modern Tibetan songs. Rap has become popular especially among young Tibetans in exile. A recent example of resistance through rap is the song RESPECT ${ }^{12}$ in response to a Chinese TV drama series entitled Tibet's Secret, whose portrayal of Tibetan society has enraged

12 This rap song, by the Tibetan rap group Sheep Droppings, was sung in Mandarin which ensured that its message would receive a wide audience in China. It was posted on Youku and subsequently removed. The full lyrics can be found on < vimeo.com/59539322> (visited on 29 October 2013). The following excerpt sums up the gist of the message conveyed: “This isn't about independence or separatism, this is about respect. We don't need you to change history or change the facts. Uneducated and ignorant, mendacious and deceptive. Some idiots here betray us for their own advantage." 
Tibetans. ${ }^{13}$ There are more and more Tibetan film-makers as well ${ }^{14}$ who want to participate in the global development of an internationally-recognized means of communication, but, within Tibet, imprisonment and torture are again often the price to pay when trying to depict the situation through Tibetan eyes for an international audience. After producing the film Leaving Fear Behind in Tibet, aimed at expressing the Tibetan reality to the world during the year of the Beijing Olympic Games, Dhondup Wangchen was arrested in 2008 and sentenced to six years in prison. He received the Visual Arts Guild freedom award in June 2013. ${ }^{15}$ Not only are Tibetan writers, singers and film-makers targets of Chinese censorship, even a French journalist was harassed and threatened by Chinese Embassy officials in Paris and Bangkok for a documentary on the current situation in Tibet which was aired on the French television channel France 24 on 30 May 2013. ${ }^{16}$

One of the top priorities of Tibetans is education, which is accessible especially in exile. Education is of course a means of progressing both within a global context as well as in Chinese society. Nonetheless the illiteracy rate for Tibetans in Tibet is still very high and fees for school are often difficult to afford for nomads or more modest families. Tibetan schools supported by foreign funds and run by Tibetans have been closed since they are not under Chinese government control and are considered as subversive. While still the primary language in elementary schools, Tibetan becomes an option in highschool and Chinese is the main working language if one wants to find a job. There are a number of Tibetans attending highschools in the Tibetan areas of China and they made headlines in October 2010 and again in March and December 2012

13 Tibet's Secret, by Chinese film director Liu Depin, recounts the history of Tibet during the 1930 s and 1940s in 46 episodes, as told by its main character, Tashi, a Tibetan lama.

14 Tibetan filmakers include Tenzing Sonam, Ritu Sarin and Tenzing Sherpa in exile, and Tashi Zangpo, Namgyal Lhadze, Pema Tashi and Khashem Gyal in Tibet for example (see the program for the Festival Jean Rouch, Regards Comparés: Tibet (26-29 November 2013), Paris: Institut National des Langues et Civilisations Orientales). <comitedufilmethnographique.com/>, visited on 11 November 2013).

15 This award was received on Dhondup Wangchen's behalf by his wife, Lhamo Tso, in New York. Her husband is scheduled to be released in 2014. Even if he is released before the due date, the release of prisoners is not always a cause for optimism as she explains: "The reason for my growing worry is an observation that is shared by many people: in the past few months a wave of releases of Tibetan writers and activists has taken place. The health conditions of all the released men were deplorable." <http://www.filmingfortibet .org/news > visited on 29 October 2013. 
by demonstrating against the change in textbooks from Tibetan to Chinese. ${ }^{17}$ Since 1959, one of the government-in-exile's main priorities in India has been the establishment of schools for Tibetan children and a full-scale curriculum, including scientific subjects, all in Tibetan, which they have successfully managed to implement. Most Tibetans in India also speak at least English and Hindi besides their mother tongue. The Dalai Lama himself encourages the learning of Chinese for practical reasons, albeit not to the detriment of Tibetan. Indeed, maintaining one's mother tongue helps uphold one's identity, whereas Chinese is useful for professional purposes. In the West, most Tibetan families try to make sure their children are schooled in the Tibetan language as well as being fluent in the language of their country of residence. In the United States, Tibetan language classes are usually held on Sunday. In September 2013, Tibetan language teachers attended the 3 rd Conference of the North American Language Schools in New York to discuss a standardized national class syllabus, class textbooks (Levels I to III) and the creation of a website. ${ }^{18}$ The 4 th Conference is to be held in 2014 in Washington D.C. The level of organization of this event points to the importance given to maintaining their language by the Tibetan community.

Another measure of Tibetans adaptation to the modern world is their political evolution and education outside of China. The desire of populations for democratic forms of government often seems to follow in the wake of globalization, although democratic governments per se still seem to be mostly limited to the West or to developed countries. Ironically, when one considers the Chinese discourse of the liberation of the Tibetans by the Chinese from feudalism and serfdom, it is in fact democratic governments in the world which have been the main models of inspiration for the Tibetans in exile while Tibetans in China continue to negotiate their cultural survival under an atheist Communist government. Over time, Tibetan society in exile has itself adopted more democratic modes of government, ${ }^{19}$ with an elected Parliament, a Prime

17 <www.theguardian.com/world/2010/oct/22/tibetan-school-pupils-protest-language -china>, visited on 7 August 2013. This imposition of the Chinese language to the detriment of Tibetan can be interpreted in different ways: a means of standardizing education, of saving money, or of erasing ethnic identity. For Tibetans, the last explanation defines what they are experiencing.

18 The 1st and 2nd Conferences for North American Tibetan Language Schools were held in Michigan (2008) and in the San Francisco Bay Area (2012).

19 The Tibetan Parliament in exile is composed of 44 delegates elected for 5 years and meets during two yearly sessions (March and September). Representation is based on affiliation to one of the three traditional regions of Tibet (U-Tsang, Amdo and Kham), to one of the 
Minister and regular elections. The limits of the democratic model are apparent in the lack of multiple political parties, a situation which appears to have just started to give raise to serious debate. When the Dalai Lama decided to step down from his political role, a Harvard-educated Tibetan, Lobsang Sangay, was elected as the first Prime Minister of the Tibetan government-in-exile on 8 August 2012, by 50,000 Tibetans. One of the Prime Minister's specificities is his willingness to engage in dialogue with Chinese abroad. Women are also represented in the government: the Minister of Information and Foreign Affairs, Ms Dicki Chhoyang, is one such example. Female Members of Parliament include Miss Tenzin Dhardon Sharling, Mrs Dolma Tsering Teykhang, Mrs Bhumo Tsering, Mrs Juchen Konchok, Mrs Youdon Aukatsang, Miss Yangchen Dolkar, Mrs Gang Lhamo, representing a ratio of one to six in comparison to male members. Another example of this inspiration based on institutional models from the United States is the "Tibet Corps" which has been created in order for young educated Tibetans to share their talents and to support various institutes mainly connected to the Central Tibetan Administration.

Tibetans struggle daily to uphold their language, religious practices, and traditions, whether within China or in the world abroad. A very symbolic form of transnational non-violent Tibetan protest action has recently arisen in the form of Lhakar ("White Wednesday") both inside and outside Tibet. ${ }^{20}$ The term refers to the birthday of the Dalai Lama which falls on a Wednesday, and on this one day of the week, Tibetans make an effort to speak Tibetan, to dress in Tibetan clothes, to eat Tibetan food and to buy Tibetan products. ${ }^{21}$ Especially outside of Tibet, this requires adapting to a daily schedule and environment which may not be conducive to expressions of ethnicity, except in the privacy of one's home or with friends. This activity can be seen as an innovative form

five traditional religious schools, or to the diasporas of Europe and North America. There is however no multiparty system as of yet and the Dalai Lama still has an influential role. (“Avancées et limites da la démocratie tibétaine," Diplomatie, n.63 (juillet-août 2013), 39). $<$ world.time.com/2013/04/17/tibetans-turn-to-alternative-protest-as-self-immolationsprove-futile/>, visited on 7 August 2013 .

21 As expressed on the lhakar.org website: "In recent years since 2008, Tibetans in Tibet and in exile have taken diverse Lhakar Pledges, resolving to boycott Made-in-China products, or to go vegetarian every Wednesday, to speak pure Tibetan, or to read a Tibetan newspaper once a week, or to wear chuba every Wednesday, etc. Through these pledges and actions, Tibetans are coming together in the greatest noncooperation movement Tibet has ever seen." <lhakar.org>, visited on 28 October 2013. Embracing vegetarianism is supposed to help prolong the Dalai Lama's lifespan. A chuba is a traditional piece of female or male clothing. 
of cultural resistance to modern standards imposed through either colonialism or globalization covering language, clothes, food and consumption. This form of resistance is inspired by past examples of other minorities' pacifist methods of civil disobedience, especially under the aegis of Gandhi or Martin Luther King. One can also take Lhakar pledges and join Lhakar vigils (in this case, outside of Tibet). The main effects seem to be an increasing awareness of a common identity and cultural heritage to be upheld and defended through means which are available to all and which are not liable (in normal circumstances) to be met with violent retaliation.

\section{Resisting Through Globalization, Using New Tools}

The Tibetan issue is a concern for many thinkers and international associations but is often eclipsed by economic imperatives. The flexing of muscles in 2013 between China and European countries such as Germany and France on importation taxes and the threat of a "commercial war" is only the continuation of a long series of verbal sparring. There is also constant pressure by Chinese Embassies around the world on state representatives or politicians not to receive the Dalai Lama.

In turn, Tibetans use international vectors of pressure in order to obtain recognition and support. Many groups and associations have been created over the years; for example in the United States, one can cite the Us-Tibet Committee (established in 1977), Tibet Fund (1981), ICT (International Campaign for Tibet, 1987), as well as thirty Tibetan Associations. The Tibetan Youth Congress (based in India), and Students for a Free Tibet (founded in New York) both represent the aspirations of a younger generation to accelerate the rate at which the situation is changing in favour of Tibetans. Tibet Lobby Day was created in the US in 2009 and is now being instituted in other countries as well, such as Japan, Canada, Australia, India, the UK and other European countries. Tibet Lobby Day takes place in March (around the symbolic day of March 1oth which commemorates the Tibetan uprising in 1959) and is the occasion for Tibetan supporters to meet and lobby representatives of the countries where they reside in order to keep the latter informed about the situation in Tibet and "to ensure the issue of Tibet is kept high on the agenda of their government."22 Many cultural associations, such as Rokpa and Tibet

$22<$ www.studentsforafreetibet.org/campaigns/political-action/lobby-for-tibet>, visited on 30 October 2013 . 
Foundation, ${ }^{23}$ also strive to finance projects inside Tibet (schools, orphanages, etc.) but this aid is generally seen as foreign intervention and their efforts are in most cases stymied by the Chinese authorities. In their quest for justice, Tibetans seized Spanish Courts in 2008 in an attempt to prosecute Chinese leaders for human rights abuses. In October 2013, Spain's National Court agreed to hear charges of genocide against Hu Jintao who was Communist Party Secretary of the Tibet Autonomous Region between 1988 and 1992 and oversaw a crackdown on anti-Chinese riots in 1989. The timing coincides with the expiration of his diplomatic immunity. ${ }^{24}$

Tibetans have struggled since 1959 to have their country recognized by international instances. So far this has produced very little effect apart from raising sympathy for the Tibetan cause. As early as 1960, the nongovernmental International Commission of Jurists, composed of eleven international lawyers, had produced a report entitled Tibet and the Chinese People's Republic to the United Nations which accused China of genocide against the Tibetans. This report found that China had violated sixteen articles of the Universal Declaration of Rights in Tibet. Tibetans and Tibetan support groups have continuously appealed to the United Nations and other international instances over the previous six decades, but to little effect in Tibet proper. In November 2013, Chinese nationals, Tibetans and other international organizations protested the election of China to the United Nations Human Rights' Council after the review of its human rights record. ${ }^{25}$ Despite these protests, China won its seat on 12 November 2013. China's argument according to which its treatment of human rights in Tibet is a "domestic" or "national" issue which does not concern other countries is not valid as other countries are now concerned with the flow of refugees and asylum-seekers from China and Tibet, and as this issue

$23<$ <ww.rokpa.org/fra/fr/projects/tibet-prc/> and <http://www.tibet-foundation.org/page/ att>, visited on 29 October 2013 .

24 $<$ www.scmp.com/news/china-insider/article/1329293/spanish-court-indicts-formerpresident-hu-jintao-genocide-charges?page=all $>$, visited on 30 October 2013. This follows the example of the prosecution of Augusto Pinochet by a group of Spanish lawyers, on the basis of the principle of universal jurisdiction. Pressure from the Chinese government had resulted in the shelving of cases in 2008 and 2012, but the Tibet Support Committee in Spain had appealed to the constitutional Court. One of the plaintiffs, Thubten Wangchen, a Tibetan by birth, is now a Spanish citizen. <www.savetibet.org/ict -testifies-in-spains-national-court-on-chinese-leadership-policies-in-tibet/>, visited on 31 July 2013. $<$ www.washingtonpost.com/opinions/yang-jianli-china-hasnt-earned-a-spot-on-human -rights-council/2013/11/o1/a2e444da-431d-11e3-a751-fo32898f2dbc_story.html>, visited on 11 November 2013. 
has now become an international one. The Tibetan government-in-exile itself finally entered the world stage in 1991 by becoming a founding member of the Unrepresented Nation's and People's Organization (UNPO). The Dalai Lama also gained international recognition by receiving the Nobel Peace Prize (which he dedicated to the Tibetan people) in December 1989 and was awarded the Congressional Gold Medal by the us Congress on October 17th, 2007. If the Dalai Lama has become an international icon and almost attained "rock star" status according to the words of a recent interviewee, ${ }^{26}$ he is still qualified as a "splittist demon" by the Chinese authorities. ${ }^{27}$ The Dalai Lama has been a constant representative and spokesperson for the Tibetan cause for six decades during his constant travels around the world, even as he gives conferences on various subjects, Buddhist teachings and initiations, fulfilling his role of Buddhist monk and teacher. He has stepped down from political responsibility but continues to be the reference point of the global Tibetan community, inside and outside of Tibet. The aspiration of the majority of Tibetans is to be able to meet him face-to-face one day. But for many Westerners, the Dalai Lama has become an important figure as well. He has published or co-authored around fifty books in English, thus gaining an international readership as well as becoming a global spiritual reference.

But what do Tibetans offer the world community as a minority ethnic group? Many of them still dream of going back to their homeland one day and see their establishment in India or the West as a temporary stepping stone. In their projecting a "Tibetan" future for Tibet, new theorizations on the Tibetan space as a possible zone of peace and environmental conservation for the world have recently been put forward, in particular by religious leaders in exile, first and foremost by the Dalai Lama ${ }^{28}$ but also by the 17 th Gyalwa Karmapa. ${ }^{29}$

26 Tim Boyd, President of the Theosophical Society in Chicago which hosted the Dalai Lama's recent visit to Chicago. Skype interview conducted by author on 17 May 2013 .

27 The Dalai Lama has turned this into a joke and calls himself a "sleeping demon" which, added to his own qualification of himself as a Marxist at heart, is a good illustration of the Tibetan sense of humour.

28 The Dalai Lama presented the 5-point Peace Plan in Washington in 1987, one of the five points being the establishment of Tibet as a demilitarized zone. The Strasbourg Proposal addressed to members of the European Parliament in June 1988 reformulated the same points.

29 The 17th Gyalwa Karmapa is one of the main Tibetan hierarchs whose authority is widely recognized by most Tibetans. The current incarnation is a matter of dispute (two incarnations were recognized, one in India and one in Tibet). The latter received official recognition by the Dalai Lama and escaped from Tibet at the beginning of the new millennium (28 December 1999 to 5 January 2000) at the age of fourteen, making international 
This is in sharp contrast to the current exploitation of the natural resources of Tibet (which is, ironically or not, called the "Western treasure-house" in Chinese) by the Chinese and of their use of Tibetan bases for nuclear-missile silos and for the possible current or future stockpiling of nuclear waste. The strategic importance of Tibet as the water source for a large part of Asia also extends its geophysical relevance beyond the borders of China. While maintaining an iron grip on the Tibetan minority within Tibet, the Chinese government is also encouraging the development of Tibet into a main tourist attraction for Chinese Han as we have already mentioned. However, international standards of heritage do not seem to apply in Tibet. The current destruction of old Lhasa is of concern not only to Tibetans but to many instances around the world, and the UNEsco World Heritage Committee was petitioned on 26 June 2013 on this issue. ${ }^{30}$ Tibetan supporters have also called for a boycott of InterContinental Hotel which plans to open a new luxury hotel in Lhassa in 2014-InterContinental Resort Lhasa Paradise-since the hotel will most probably not employ Tibetans except in menial tasks and will accommodate wealthy Chinese businessmen and Party cadres. ${ }^{31}$

Much reflection is taking place nowadays in the world on viable models for the perennity of society/ies. Common keywords include the environment, sustainability, responsability, and respect. The Dalai Lama uses the expression of "universal responsability," and humanism. Spirituality as a possible value for the future might also be added in contrast to materialism, individualism and consumerism. One of the main characteristics of Tibetans in general is their loyalty to Buddhism, although its transmission is not always easy to maintain either under an atheist Communist rule or in a global world driven by materialism and consumerism. On the other hand, Tibetan Buddhism has become quite popular among Western societies and many people have embraced it as a daily practice. In such a way, aspects of the Tibetan culture and language are also spreading on a global level. Nevertheless, with the encouragement of the Dalai Lama, this form of spiritual technique is being synchronized with

headlines. Since his arrival in India, he has been able to continue his religious training and to travel to the United States. See <www.nytimes.com/200o/o1/31/world/buddhist -s-escape-from-tibet-by-car-horse-and-plane.html $>$ and <http://kagyuoffice.org/in -india/the-karmapas-great-escape-december-28-1999-january-5-200o/>, visited on 25 October 2013 .

30 <www.change.org/en-GB/petitions/help-stop-the-destruction-of-my-home-lhasa-tibet>, visited on 31 July 2013.

$31<$ www.theguardian.com/world/2013/may/23/tibet-activists-boycott-intercontinentalhotel-plan>, visited on 7 August 2013. 
science through research on the effects of meditation for example and regular international seminars are hosted by the Mind and Life Institute which has links to м.I.т. Tibetan meditation techniques are thus entering the global mainstream therapeutic field without always carrying the label of "Buddhist." Tibetans are thus also participating in the development of a "global Buddhism" by perpetuating Buddhist practice within their communities but also by transmitting Tibetan teachings and techniques to those interested in balancing the materialism and consumerism of current global societies with some measure of spirituality.32

\section{Conclusion}

It is true that globalization has advanced modernization, transformation, and consumerism in China and by repercussion has affected Tibetans in China, through the forced modernization of Tibet (exploitation of resources, Disneyfication of the culture and religion). As explained by Thubten Gyatso (the representative of the Tibetan community in France), Tibetans do not reject modernization but want to be able to conduct it on their own terms, with a respect for religion and culture. ${ }^{33}$ Although they may be considered as uneducated and backward by the dominant Han population, they are technosavvy and keen on education. They often have a feeling of being "bought" by Chinese material goods. Contrary to the case of some minorities, globalization has become a medium of resistance and a tool of survival for the Tibetan community which has seized every opportunity to use modern means of communication inside and outside Tibet and economic openings in exile to uphold its identity and cohesion as a minority group, one who, so far, has chosen to follow the strategy of non-violence advocated by their moral and spiritual leader. This choice of non-violence seems to be the only available option to a people who are profoundly Buddhist at their core.

This deliberate and enduring choice of non-violence poses a moral question or standard on the international level, especially for Western democratic societies which usually favour economic considerations over human ones. Nevertheless, the Tibetans pacifist approach to resistance may explain the

\footnotetext{
32 There is much to be said about the phenomenon and the spread of a "global Buddhism," but the subject lies beyond the scope of this article.

33 Debate on France 24 on 30 May 2013. <http://www.france24.com/fr/20130530-debat -partie2-tibet-chine-droits-homme-dalai-lama-xi-jinping $>$, visited on 1 November 2013.
} 
"capital of sympathy" they usually benefit from, which often makes it easier for Tibetan refugees to gain asylum status compared to other minority groups, or to find a way to the West through government resettlement programs. But this image of a model refugee minority does not carry much weight apart from a moral one in the economic and political strategies being played out on the board game of the world, however much many Tibetans would wish to see Western countries intervene directly to help them in China. Apart from moral condemnations and reports on the situation of human rights, there seems to be little these countries can do when facing China. Up to date, ${ }^{34}$ the 123 selfimmolations of Tibetans, in Tibet (as well as in Nepal and India), mainly of monks but also of nuns, lay men and women (parents in all of the latter cases), and teenagers, have had very little impact on the outside world. This impact depends mainly on the amount of media coverage which might be devoted to the subject, but international headlines and news focuses change quickly. What little news coverage there may be in China is used to blame the Dalai Lama and the government-in-exile for incitation. Outside of China, the media around the world usually relate the very difficult conditions faced by the Tibetans in their homeland which lead to these self-immolations. The question remains of the motivation of those who immolate themselves. Even if many Tibetans themselves do not agree on this radical choice, it is usually explained through the idea of self-sacrifice and as an act of despair for lack of any other means of expression. In making this choice, self-immolators exercise no violence on the Chinese, and there is no destruction of property or people except of themselves. If one wants to be cynical, one could add that the only hardship added to the burden of Chinese soldiers in Tibet (300,000 or one fifth of the Chinese Army; one soldier for twenty Tibetans) is that they must now also carry fire-extinguishers in addition to their regular weapons.

One could add one last specificity the Tibetan people as a minority have to offer the world: their sense of humour and enduring good spirits in the face of hardship. This aspect of their resilience after sixty years of colonization and exile can be seen as a new global tool for reaching-out to the international community and showing it that the Tibetans are far from having given up but that they have managed to maintain their fundamental good humour in the face of

The 123rd self-immolation was that of monk Tsering Gyal in Tibet on 11 November 2013 . His last words were: "Today, I burned myself for the re-union of Tibetans. My only hope is the unity among Tibetans and the preservation of the Tibetan language and tradition. If we do that, all the Tibetans will be re-united." <www.phayul.com/news/article .aspx $?$ id $=34213 \&$ article $=$ Golok + self-immolator + Tsering + Gyal + succumbs + to + burns $\& \mathrm{t}=1 \& \mathrm{c}=1>$, visited on 12 November 2013 . 
hardship and will continue to do so as long as necessary. This capacity to not give in to despair while being able to make fun of oneself or to see the irony in difficult situations could be seen as a new kind of global political strength.

\section{Bibliography}

\section{Books}

A.M. Blondeau and Katia Buffetrille. Le Tibet est-il chinois? (Albin Michel, Paris, 2002). J. Knaus, Orphans of the Cold War. America and the Tibetan Struggle for Survival (Public Affairs, New York, 1999).

D. Lopez Jr. Prisoners of Shangri-La. Tibetan Buddhism and The West (The University of Chicago Press, Chicago, 1998).

D. Norbu. Tibet, The Road Ahead (Random House, London, 1998).

\section{Articles}

J.M. Hess. "Statelessness and the State: Tibetans, Citizenship, and Nationalist Activism in a Transnational World," International Migration, Vol. 44, Issue 1 (March 2006): 79-103.

"L'Avenir du Tibet." Diplomatie, n. 63 (juillet-août 2013): 30-57.

"Security in Tibet: Grid locked." The Economist (22 June 2013): 53-54.

T. Sullivan. "A World without Dalai Lama. Tibetans and the Spiritual Leader Himself Ponder the Inevitable," The Washington Times (17 June 2010). <http://www.washington times.com/news $/ 2010 /$ jun $/ 17 / a-w o r l d-w i t h o u t-d a l a i-l a m a / ? p a g e=a l l>$.

"Tibet's Future: The Limits of Despair." The Economist (9 March 2013): 51-52.

"Tibet Policy: Bold New Proposals." The Economist (22 June 2013): 53-54.

E. Yeh. "Will the Real Tibetan Please Stand Up! Identity Politics in the Tibetan Diaspora." Tibet, Self, and the Tibetan Diaspora, Voices of Difference (Proceedings of the Ninth Seminar of the IATs, 2000), K.P. Christiaan, (ed.), Brill (2002): 229-254.

\section{Internet Sites Consulted in Researching this Article}

http://highpeakspureearth.com/.

http://lhakar.org.

http://tibetanculture.org/.

http://wwwl.voanews.com/tibetan-english/news/tibet/.

http://www.ciolek.com/WWWVLPages/TibPages/tib-politics.html.

http://www.freetibetanheroes.org/home.php/.

http://www.freetibet.net/.

http://www.friends-of-tibet.org/.

http://www.humanrightsfirst.org/asylum/stories/storie-o1.htm. 
http://www.phayul.com.

http://www.rangzen.net/.

http://www.savetibet.org.

https://www.studentsforafreetibet.org.

http://www.tanc.org/US-human-rights-report-on-china/.

http://www.tcdailyplanet.net/article/2008/04/03/seiu-healthcare-s-jigme-ugen-first

-tibetan-elected-union-leader-u-s.html.

http://www.thetibetconnection.org/.

http://www.thetibetpost.com/en/.

http://www.tibetaid.org/.

http://www.tibetan-alliance.org/chicago_tibetans.html.

http://www.tibet.ca/en/newsroom/wtn/2462.

http://www.tibetangeeks.com/.

http://www.tibetanpoliticalreview.org/.

http://www.tibetcorps.org.

http://www.tibet-foundation.org/.

http://www.tibetfund.org/.

http://www.tibethouse.us/resources/directory/u.s.-tibet-organizations/.

http://www.tibetjustice.org.

http://www.tibetoffice.org/en/.

http://www.tibet.org/.

http://www.tibetsun.com/.

http://youngtibet.com/. 